\title{
UM ABANADOR E UMA ARENGA: CONTRADIÇÕES E DESLOCAMENTOS NO TRÂNSITO DOS SENTIDOS
}

\author{
SÓSTENES ERICSON ${ }^{1}$; LUCAS MANCA DAL'AVA ${ }^{2}$
}

\author{
Faculdade de Letras, Campus A.C. Simões, Universidade Federal de Alagoas \\ Av. Lourival Melo Mota, S/N, Tabuleiro do Martins \\ 57072-970 - Maceió - AL - Brasil \\ Instituto de Estudos da Linguagem, Universidade Estadual de Campinas \\ Rua Sérgio Buarque de Holanda n ${ }^{0} 571$ - 13083-859 \\ Cidade Universitária Zeferino Vaz - Campinas - SP - Brasil

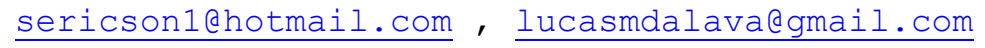

\begin{abstract}
Resumo. O propósito deste artigo é analisar a produção de sentidos, enquanto efeito do interdiscurso no intradiscurso. Filiados à análise materialista inaugurada por Michel Pêcheux, observamos que, pelas contradições e deslocamentos, os discursos reforçam o imaginário social sobre o macho como dominante na sociedade burguesa, enquanto fratura uma suposta representação homogênea da mulher, reforçando uma dualidade entre figuras postas em condição antagônica - a santa e a puta.

Palavras-chave: discurso; contradição; deslocamento; sentidos.
\end{abstract}

\begin{abstract}
The purpose of this article is to analyze the production of senses as an effect of the interdiscourse in the intradiscourse. Affiliated to the materialistic analysis inaugurated by Michel Pêcheux, we observed that, by contradictions and displacements, discourses reinforce the social imaginary about the male as dominant in bourgeois society, while fracturing an alleged homogeneous representation of women, reinforcing a duality between figures placed in an antagonistic condition - the saint and the whore.
\end{abstract}

Keyword: discourse; contradiction; displacement; sense.

\section{INTRODUÇÃO}

De acordo com Orlandi (2003), o texto é entendido como materialidade discursiva (uma unidade de análise), na qual a memória ganha corpo. Na Análise do Discurso (doravante AD), "trata-se do texto como forma material, como textualidade, manifestação material concreta do discurso, sendo este tomado como lugar de observação dos efeitos da inscrição da língua, sujeito a equívoco na história" (ORLANDI, 2001, p. 78). Cabe

\footnotetext{
${ }^{1}$ Doutor em Letras e Linguística pela UFAL. Docente no Programa de Pós-Graduação em Linguística e Literatura (PPGLL) da UFAL.

${ }^{2}$ Doutorando em andamento em Linguística na UNICAMP.
} 
destacar que um ponto primordial para a materialidade discursiva é o enunciado, uma vez que este constitui o conjunto de sentidos mais elementar que pode ser particularizado dentro do discurso (BARROS, 2015, p. 75).

A questão a que nos propomos analisar neste trabalho não se deu a conhecer a priori, uma vez que os recortes aqui analisados não foram selecionados ao mesmo tempo, cabendo situar algumas especificidades desse encontro. $\mathrm{O}$ abanador foi apresentado por ocasião da oferta de uma disciplina de verão durante estágio pós-doutoral, e a arenga, embora não a tenhamos presenciado, foi contada em uma conversa informal com amigos pernambucanos.

Cabe lembrar que o substantivo feminino arenga, no sentido dicionarizado, refere-se a um discurso que se pronuncia em público, perante uma assembleia, bem como a qualquer discurso ou oração fastidiosa, impertinente, sendo sinônimo de alocução, disputa, arrazoado, briga, desentendimento etc. (FERREIRA, 2014), interessando para a presente análise os últimos sinônimos, exemplificados numa disputa verbal no trânsito durante o carnaval.

Considerada, do ponto de vista religioso, como uma festa pagã, o carnaval é a maior festa popular brasileira, em torno da qual enunciados diversos, aqui considerados como "os elementos do saber próprio a uma FD” (COURTINE, 2009, p. 100), são materializados, a exemplo de folia de Momo, blocos de carnaval, escolas de samba, maracatu, marchinhas, entre outros. Tais elementos, no entanto, decorrem de manifestações culturais espontâneas imbricadas nas diferentes práticas de linguagem, implicando na constituição do sujeito discursivo folião/foliã, em suas diversas expressões. Ocorre que, por ocasião de uma campanha governamental de serviço durante o carnaval, o discurso governamental produziu uma fragmentação da forma-sujeito, o que se deu, por conseguinte, no interior da própria formação discursiva, como Indursky (2003) identificou, ao analisar o enunciado "Lula lá", a partir dos pressupostos apresentados por Pêcheux (2006), no que diz respeito ao acontecimento discursivo.

Um ponto em comum, a princípio, entre o abanador e a arenga, de onde foi extraído o corpora (COURTINE, 2006) desta análise, seria o período de carnaval, em que o atravessamento do discurso governamental através da campanha "Se beber, não dirija" produziu um acontecimento enunciativo, implicando em distinções entre foliões/foliãs (os/as que não bebem e não dirigem, os/as que bebem e não dirigem, e os/as que bebem e dirigem), orientadas a partir da relação entre beber (ingerir bebida alcóolica) e dirigir, enunciada pelo Estado sob a forma de advertência. A retomada desse recorte possibilita analisar a produção de sentidos, nas contradições e deslocamentos daí suscitados. A formulação desse objetivo, todavia, pressupõe a identificação da questão que o suscita, sendo esta posta pelo objeto em análise: como as contradições e deslocamentos produzem sentidos do interdiscurso no intradiscurso e quais os seus efeitos?

A formulação de tal questão, bem como a busca por uma resposta possível têm na AD sua ancoragem. Por esta razão, recorremos a Pêcheux, para considerar que as condições de produção do discurso são "determinações que caracterizam um processo discursivo, inclusive as características múltiplas de uma situação concreta que conduz à produção do sentido linguístico" (PÊCHEUX; FUCHS, 1997, p. 183), tendo em conta que o sentido vai além de sua materialidade linguístico-sintática. 
Os sentidos produzidos, em condições de produção dadas, decorrem da imbricação de dois componentes: intradiscurso e interdiscurso. Tais componentes são submetidos aos efeitos ideológicos dentro das formações discursivas. Ainda de acordo com Pêcheux, uma formação discursiva é "aquilo que, numa formação ideológica dada, determinada pelo estado da luta de classes, determina o que pode e deve ser dito (articulado em forma de uma arenga, de um sermão, de um panfleto, de uma exposição, de um programa etc.)" (PÊCHEUX, 2009, p. 147), sendo estes os pressupostos que sustentam a presente análise.

\section{UM ABANADOR - UM GESTO DE ANÁLISE NO QUE ESCAPA}

Embora tenhamos tomado um abanador como parte do título desse trabalho, lembramos que não é nosso propósito analisá-lo. O interesse se volta ao discurso aí materializado, considerando suas filiações discursivas (interdiscurso) e seus efeitos de sentido. Nesse movimento, formulamos três sequências discursivas, fazendo uma distinção entre elas quanto à posição em que comparecem no abanador, aqui considerando o efeito de antecipação.

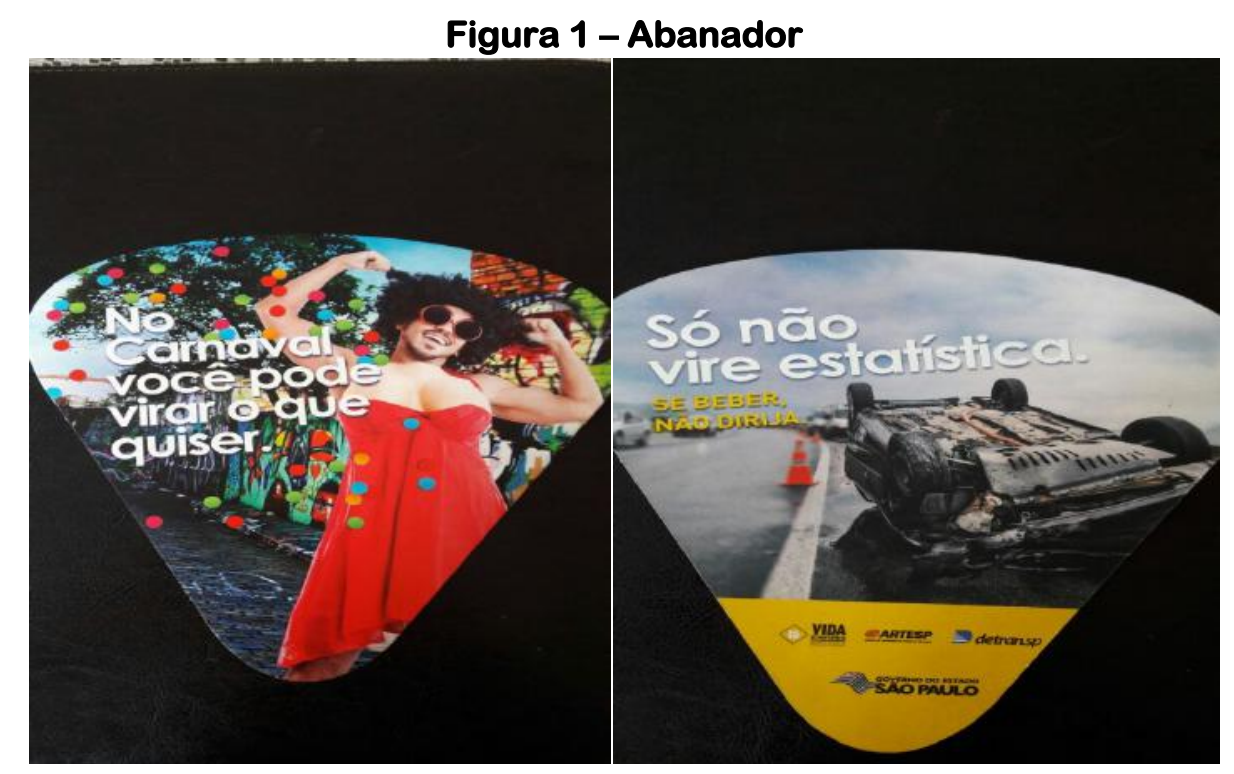

Fonte: DETRAN/SP, 2017.

$\mathrm{Na}$ figura do abanador, verso e avesso são postos em relação, contrapondo a alegria do carnaval (verso) com a tristeza de um acidente de trânsito (avesso). Trata-se de uma campanha que se utiliza da propaganda governamental de serviço, com o objetivo de sensibilizar motoristas quanto aos acidentes de trânsito ocorridos no carnaval, especialmente os acidentes relacionados ao consumo de bebidas alcóolicas. Todavia, embora o objetivo acima apontado pareça ser justificado em razão das estatísticas dos acidentes de trânsito no estado de São Paulo, há algo que escapa. É nessa brecha, então, que pretendemos mobilizar os dispositivos teórico-analíticos da teoria materialista do discurso, para a análise das sequências discursivas (SD) a seguir:

SD1 - "No carnaval você pode virar o que quiser." 
$\mathrm{Na}$ superfície linguístico-discursiva, o sujeito da frase (você) é interpelado em interlocutor pelo sujeito da enunciação (o Detran), que em posição de autoridade governamental assume a condição de estabelecer o que o interlocutor (você) pode virar no carnaval (o que quiser). Esse efeito de temporalidade (no carnaval) assume também uma condição restritiva, uma vez que "você" não "pode virar o que quiser" quando quiser, mas [apenas] no carnaval; ao menos no que apresenta a SD em sua imediaticidade.

De acordo com Guimarães (2002, p.23), uma cena enunciativa "se caracteriza por constituir modos específicos de acesso à palavra dadas as relações entre as figuras da enunciação e as formas linguísticas". Vejamos que o caráter informal, de proximidade, entre o locutor (sujeito da enunciação) e o interlocutor (sujeito da frase), chamado de "você" confere uma distinção entre o eu (Detran) e o você (motorista no trânsito do/no estado de São Paulo), numa condição assimétrica de poder entre a voz do que manda/enuncia e o outro que atende/obedece. A relação de poder ganha maior contorno ao estabelecer para o outro que ele pode, o que ele pode, e em que circunstância ele pode.

Partindo do pressuposto de quem é o interlocutor (você homem), tem-se então a abertura para certa instabilidade entre o que ele é e o que pode virar (sem deixar de ser). É nessa possibilidade transitória que se abre espaço para "você virar o que quiser" no carnaval. Nesse sentido, "o que quiser"/tudo supõe uma amplitude ou procura abarcar a totalidade de possibilidades, embora com contornos definidos, razão pela qual ressaltamos o caráter de suposição.

No entanto, partindo da superfície linguístico-discursiva, é possível recuperar no imaginário social que "no carnaval, o homem (você/interlocutor) pode virar o que quiser". Por esta via, "virar" produz um efeito de permissividade ao homem (heterossexual) que se veste de mulher no carnaval e, ao mesmo tempo, reforça um imaginário masculino caricaturado sobre um tipo de representação das mulheres. A possibilidade simplista do homem se vestir de mulher põe em perspectiva, de modo ampliado, que "masculino" e "feminino" são efeitos produzidos socialmente por meio das coisas que fazemos, conforme Butler (2017) afirma: "gênero é a estilização repetida do corpo, um conjunto de atos repetidos dentro de uma estrutura rígida e reguladora que se consolida, com o passar do tempo, produzindo o que aparenta ser substância, uma espécie 'natural' de ser" (p. 33, grifo da autora).

Embora o efeito de heteronormatividade e as estratégias discursivas dos gêneros não possam ser reduzidos ao binarismo, o recorte em análise possibilita inferir que o primeiro caso exige do homem que reforce características daquilo que, socialmente, o identifica como homem heterossexual - força, virilidade, expressão física masculinizada, como a manutenção de pelos corporais, por exemplo. Por sua vez, a figura de mulher assumida no vestuário do homem heterossexual durante o carnaval dialoga com o exagero, com a valorização de atributos corporais como os peitos e as pernas, sendo uma aproximação com uma figura erotizada da mulher no fetiche masculino.

Distanciando-se da imagem materna/da santa (Maria), a representação assumida nessas circunstâncias reifica, no corpo do homem heterossexual, a imagem da puta (Eva) que lhe dá prazer exatamente por conta da transgressão. Nesses termos, o que pode (homem virar mulher) e o que não pode (homem virar puta) se fundem em um mesmo corpo, que agora ressignificado silencia as contradições de sua composição e pela comicidade faz deslizar 
os fundamentos históricos, sociais, políticos e ideológicos que o sustenta e perpetua, a figura do homem macho e a da mulher puta, enquanto produções de gênero.

Considerando o caráter histórico da memória discursiva, tem-se em conta que sua constituição é originada na realidade objetiva, de onde o sujeito do discurso, em suas filiações ideológicas, materializa as relações de identificação e/ou resistência às formações discursivas no interior das quais os sentidos são produzidos.

De acordo com Zoppi-Fontana,

parte integrante do interdiscurso no qual se delimitam, as FD representam regiões de estabilização da memória discursiva que se organiza por processos de reformulação parafrástica em movimento contínuo de reconfiguração. $O$ interdiscurso afeta a materialidade linguística das sequências discursivas, as quais se apresentam, assim, como vestígios do movimento histórico sem fim das FD nas relações de dominação, subordinação, antagonismo e aliança que definem sua configuração. (ZOPPI-FONTANA, 2002, p. 179)

A estabilização da memória no interior das formações discursivas não implica, no entanto, uma permanência de seus elementos constitutivos (como o já-dito, o pré-construído), mas está sempre sujeita aos processos discursivos de outras formações discursivas, o que possibilita a "produção de novos sentidos atribuídos a uma palavra em relação aos sentidos já existentes, constituindo-se uma inesgotável relação entre discursos que representam uma ou mais formações ideológicas" (AMARAL, 2005, p. 34).

A próxima SD foi extraída do avesso do abanador e, em oposição à alegria atribuída ao carnaval e à transgressão da regra social sobre o homem vestir-se de mulher (virar mulher), põe em causa o argumento das estatísticas de trânsito quanto aos acidentes e mortes. Nesse momento, "pode virar o que quiser" não mais se refere a tudo, pois pela restritiva abre uma exceção:

\section{SD2 - Só não vire estatística.}

Aqui não há necessidade de apresentar dados oficiais sobre os acidentes de trânsito porque a imagem se coloca como um elemento de argumentação, que sustenta a restrição e o imperativo empreendido para produzir sentidos de responsabilidade no interlocutor/você (homem heterossexual). Essa exceção ao "o que quiser" passa a se constituir uma regra que, pela articulação, colabora na produção de efeito de verdade nos argumentos apresentados.

$$
\text { SD3 - Se beber, não dirija. }
$$

Esta foi a SD referencial, em torno da qual, a propaganda foi elaborada. Conforme Courtine (2009, p. 108), a sequência discursiva de referência

será relacionada a um sujeito de enunciação como a uma situação de enunciação determináveis em relação a certo número de coordenadas espaço-temporais e mais geralmente circunstanciais (tempo da 
enunciação, lugar da enunciação, circunstâncias da enunciação, que incluem a presença de alocutários determinados...).

Considera-se, então, que o funcionamento da SD3, a partir do que vinha sendo apresentado (inclusive pela imagem de um carro capotado), está baseado na condicional "se..., não" em que os complementos são colocados em oposição. Nesses termos, beber se opõe a dirigir e isso dialoga com uma memória que procura estabilizar que "bebida alcóolica e direção não combinam", situando-se no campo do que é proibido, daquilo que não pode.

A combinação a ser trabalhada em sua (im)possibilidade entre beber e dirigir aparece tardiamente e acaba sendo coadjuvante da combinação (ou da não combinação) entre a fusão do estereótipo do homem heterossexual e o da puta, ou de uma combinação que tornou possível que no carnaval este pode virar aquela. Esses são, portanto, alguns aspectos que antecedem o segundo momento desta análise.

\section{UMA ARENGA E OS SENTIDOS EM DISPUTA}

Nesse momento, interessa apresentar a descrição de uma disputa verbal no trânsito, entre dois homens visivelmente embriagados, presenciada por um amigo durante o carnaval de Recife em 2017.

1. Um carro bateu em outro e o motorista do carro batido desceu para tomar satisfação: - Você tá cego que não viu que eu ia passar, filho da puta?

2. O motorista do carro que bateu, incomodado com o insulto, retrucou: - Filho da puta, o quê? Cabra safado!

3. Em meio à dificuldade do diálogo e a troca de insultos, o primeiro não aceitou ser chamado de "cabra safado" e exigiu respeito: - Cabra safado, uma p...; me respeite, cachorro!

Voltamos nosso interesse para a formulação de uma SD que indica um movimento de deslocamento entre a motivação da arenga (a batida de um carro em outro) e os dizeres sobre a puta, aqui considerados como efeitos do interdiscurso no intradiscurso. As posições-sujeito do discurso aí materializado tensionam as relações de poder dentro da mesma formação discursiva, expondo alguns elementos de fricção e de ambiguidades, nos quais não se põem em causa, entre locutor e alocutário, os efeitos da advertência feita em SD3 (Se beber, não dirija), recuperando na memória discursiva, um já-lá também identificado a partir dos dizeres presentes no abanador. É o que demonstramos com base na SD a seguir:

SD4 - Você tá cego que não viu que eu ia passar, filho da puta?

Insistindo numa proximidade com o interlocutor (você), o sujeito da enunciação aqui assume uma relação de superioridade, reclamando do outro, ao tempo em que lhe imputa a culpa. $\mathrm{O}$ argumento em torno do qual a culpa é atribuída ao motorista do carro que bateu, no entanto, pelo efeito metafórico recupera o campo da visão (ou da não visão) para daí apontar que nessas condições, há um funcionamento discursivo que decorre de 
uma construção possível de significar, a partir do que constitui o seu sítio de significação, o que apresentamos, por paráfrase, a seguir:

5. (Só) um cego (alguém) não veria que eu (um carro) ia passar.

4. Se alguém está cego não vê que eu (um carro) vou passar, logo é um filho da puta.

3. O cego (você) que não viu que eu (um carro) ia passar é um filho da puta.

2. O cego (você) é um filho da puta.

\section{Você é um filho da puta}

Chama atenção o processo de identificação do eu/enunciador com o carro no qual se deslocava, uma vez que não se tratava de um atropelamento, mas de uma batida entre dois carros. Esse processo de personificação torna-se necessário, uma vez que se o carro não pode reclamar, então, o motorista (proprietário ou não) assume a condição de defender os interessas do bem móvel prejudicado.

O estudo de Cameron (2010, p. 129-130, grifo da autora) demonstrou que, em linhas gerais, "a fala masculina é competitiva, hierarquizada, centrada em tópicos 'impessoais' e na troca de informação, e que evidencia gêneros conversacionais como piadas, troca de insultos e resultados de jogos". Na SD em análise, vê-se que o argumento sustentado, inicialmente, na associação a um cego desliza para uma associação com o "filho da puta", trazendo a puta numa menção à memória de um dizer sobre o "filho da puta", um filho sem pai, um enjeitado, um filho de qualquer um. Considera-se que ser "filho da puta" é uma ofensa e, portanto, esta passa a constituir uma estratégia de persuadir o outro a assumir a culpa (expressão do discurso religioso), não somente por ser responsável pela batida, mas também, e por conta disso, de ser considerado "filho da puta". A essa altura, o diálogo já não se coloca mais em torno de quem teve responsabilidade sobre o acidente, mas se desloca para as consequências do insulto e, principalmente, para a não identificação do interlocutor com essa posição - de "filho da puta", o que o leva a revidar:

\section{SD5 - Filho da puta, o quê? Cabra safado!}

Não se trata de se contrapor à responsabilização pelo acidente, mas de não aceitar a associação atribuída pelo locutor. No lapso de segundos entre os dizeres que originaram as duas sequências, o acidente é silenciado e a troca de ofensas assume a condição de sobredeterminação. Cabe apontar que, enquanto recusa a atribuição de "fillho da puta" pelo questionamento que funciona como negativa, o interlocutor convoca (conscientemente ou não) do imaginário a figura do "cabra safado", em condição pejorativa, uma vez que em certas circunstâncias tal expressão também pode representar, no nordeste, uma condição de elogio, a exemplo, do ideário do homem "macho" que assume ser "cabra safado", em referência a sua masculinidade demonstrada no uso da força física, na promiscuidade sexual etc.

Observa-se que um insulto é devolvido com outro e nessa construção, "filho da puta" e "cabra safado" assumem uma condição de suposta equivalência. Puta e cabra assumem, respectivamente, estereótipos de mulher e de homem, e na metáfora do segundo (em associação à cabra, animal que resiste às secas do sertão nordestino) reside a necessidade de adjetivação, fazendo distinção com o "cabra da peste", ao tempo em que "safado" 
recupera uma memória sobre a safadeza e, nesse momento, o homem safado e a puta parecem se encontrar.

Todavia, a condição de sobreposição assumida pelo interlocutor parece não se identificar com essa associação, uma vez que na construção "cabra safado" e "fillho da puta" foram postos como equivalentes e, mais uma vez, tem-se um efeito de negação que expressa as ambiguidades da formação discursiva em questão, conforme observamos na próxima SD:

$$
\text { SD6 - Cabra safado uma p...; me respeite, cachorro! }
$$

Ao tempo em que se opõe à designação "cabra safado", talvez pelo efeito de sua equivalência a "filho da puta" como temos argumentado, o enunciador exige respeito, e substitui o "cabra" pelo "cachorro". Não se trata, em termos mais imediatos de questionar apenas como alguém que exige respeito, ao mesmo tempo, chama o outro de cachorro; mas de considerar também como que "cabra" e "cachorro" se equivalem, reforçando o imaginário de que o "cabra safado" é um "cachorro". Por esta via, não se trata de apontar uma contradição em "me respeite, cachorro", mas de evidenciar que os dois elementos (me respeite e cachorro) são parte de um mesmo funcionamento discursivo e se inscrevem num mesmo lugar.

Para demonstrar uma possibilidade de construção desse processo no campo intradiscursivo, apresentamos as formulações a seguir:

6. Um cabra safado é um filho da puta.

5. Um cabra safado/Um filho da puta não respeita.

4. Um cabra safado/Um filho da puta, que não respeita, é um cachorro.

3. Um cabra safado/Um filho da puta [...] é um cachorro.

2. [SE] Eu não respeito o outro, ao chamá-lo de cachorro.

1. [LOGO] Eu também sou um cabra safado, um filho da puta, um cachorro.

O movimento parafrástico acima apresenta não apenas a não contradição entre os diferentes dizeres, mas também contribui para reforçar um imaginário pejorativo sobre a puta, na sua relação com o homem "safado" e "cachorro", tensionado no "fillho" que advém dessa possibilidade. O incômodo se dá, pelo que conseguimos identificar, não pela associação do homem heterossexual à puta, mas da sua não aceitação quanto ao lugar social do filho dessa relação. A contradição talvez esteja em o homem aceitar ser o "macho" da puta e não ser o "filho da puta". No nosso gesto de análise, pensamos ser necessário observar que os papéis sociais de mãe e de puta são considerados como antagônicos nessa sociedade e isso pode ser observado no dizer "filho da mãe", funcionando em substituição a "filho da puta", mas também considerado pejorativo exatamente por sua associação. Daí, a condição do homem em ser filho remete ao papel social da mulher mãe e não se identifica com a mulher puta, aquela que socialmente assume um lugar voltado ao prazer sexual, à safadeza.

No dizer de Petherson (2009, p. 203), "a troca de serviços sexuais por uma compensação financeira ou material pode ser caracterizada como prostituição, mas também pode estar presente em relações como namoros ou o casamento", o que amplia a noção de prostituição, como também contribui para o entendimento do seu alcance na sociedade. Longe de ser "a mais velha profissão do mundo", a prostituição foi tomada pelo discurso 
sanitário de proteção ao corpo, como também pelo discurso religioso e estatal, em defesa da ordem sexual e do matrimônio (LEGARDINIER, 2009), em que pese a necessidade de perpetuação da propriedade privada, no âmbito da família monogâmica (para as mulheres).

Nas palavras de Petherson (2009, p. 204, grifos do autor),

a prostituição é uma instituição que serve à regulação das relações sociais de sexo. Assim, todo comportamento transgressivo por parte das mulheres num dado contexto pode provocar sua estigmatização como 'prostituída' ou 'puta' e levar a punições que daí decorrem.

Por esta razão (mas não somente), é preciso situar a condição da puta a partir do modo como o trabalho está posto em um dado modo de produção, uma vez que, por exemplo, sendo o sexo transformado em mercadoria, a relação sexual passa a ser de outra ordem, cabendo lembrar que "quando são homossexuais ou homens transgêneros que fornecem os serviços sexuais, isso não muda em nada a relação sexo/gênero, porque, da mesma forma que as mulheres, eles servem aos homens" (PETHERSON, 2009, p. 204). Tem-se em conta que "as relações de classe são atravessadas pelas relações de poder e dominação o sexo masculino sobre o feminino" (CISNE, 2014, p. 24), cabendo lembrar que "o primeiro contingente feminino que o capitalismo marginaliza do sistema produtivo é constituído pelas esposas dos prósperos membros da burguesia ascendente" (SAFFIOTI, 2013, p. 67).

\section{NO TRÂNSITO DOS SENTIDOS...}

Com base nos aspectos já apresentados, agora aproximamos o abanador e a arenga, para observar o funcionamento de uma dada formação discursiva, materializada numa propaganda de serviço e numa discussão de trânsito. Trata-se de um ponto de encontro entre diferentes dizeres que se articulam em torno de duas representações principais: o homem macho e a mulher puta.

Não se trata de ignorar as demais representações de gênero e o risco binário do masculino e feminino, mas de considerá-las secundariamente à posição-sujeito dominante do discurso em análise. Embora tenhamos procurado demonstrar esse funcionamento de modo mais específico, convém lembrar que aí incidem outros discursos, a exemplo do discurso religioso cristão que, com base na noção de pecado, associa à puta à pecadora (Eva) e, consequentemente, torna-a marginalizada, quando em comparação com a santa/ a mãe (Maria).

O carnaval, então, possibilita a circulação de dizeres que retomam a memória discursiva sobre a família, sobre o casamento, sobre a divisão sexual do trabalho e todas as suas consequências. A essa altura, os xingamentos são apreendidos como elementos de dizer de uma dada formação discursiva que procura estabilizar os sentidos de homem (macho) e de mulher (puta), ainda que isso se dê quando se procura sensibilizar para a prevenção de acidentes de trânsito ou mesmo quando o acidente já aconteceu.

De um lado, o homem cego, filho da puta, cabra safado, cachorro. De outro, ela, a mãe desse homem, a "proibida", a erotizada, a puta. É precisamente esse imaginário de mulher 
que vai sendo mobilizado no interdiscurso, sobre a qual não repousa a dúvida da maternidade, e sobre a qual se articula desejo, proibição/transgressão, e necessidade. Nesse último aspecto, ainda que de modo breve, cabe considerar a necessidade da puta para que a santa/mãe exista nesse papel, uma vez que de fora a puta regula o funcionamento de dentro da família heteronormativa e constituída na cultura patriarcal.

Ao poder virar uma mulher no carnaval, o homem heterossexual evoca o imaginário não da mulher de casa (do espaço privado), da mãe, da santa; mas da mulher da rua (do espaço público), da mulher de vermelho, da cor do pecado. A imagem então (re)compõe no imaginário masculino os elementos de representação da mulher puta e é essa a imagem que possibilita ao homem "macho" a fusão de sua masculinidade com o prazer da puta em um mesmo corpo.

É desse lugar que se silencia quem é o pai do filho da puta, talvez por sua impossibilidade de precisão, o que é materializado em dizeres como "filho de puta não tem pai". Por esta razão, a representação de masculinidade em tela não se identifica com o "filho da puta", ao tempo em que silencia sua participação na paternidade. O que é silenciado, no entanto, faz significar precisamente por essa condição (ORLANDI, 1993), fazendo funcionar, indiretamente, uma associação do "cabra safado", do "cachorro" com o "macho" da puta. Nesse caso, o que ocorre é uma identificação com o sujeito do discurso machista, o que comparece em outras materialidades, a exemplo de alguns gêneros musicais que evocam o homem cachorro, elogiando a sua condição "natural" de ser assim, em dizeres materializados pelo uso metafórico que lhe é constitutivo.

\section{UM EFEITO-CONCLUSÃO}

Aparentemente um abanador educativo sobre acidente e uma arenga de trânsito nada teriam a ver com as questões de gênero na sociedade capitalista. Questionando a transparência da linguagem, procuramos mobilizar os dispositivos teórico-analíticos da $\mathrm{AD}$, para demonstrar como as contradições e deslocamentos produzem sentidos do interdiscurso no intradiscurso.

Os efeitos de sustentação na argumentação em torno do que justificou a propaganda governamental de serviço (o abanador) e da arenga (os xingamentos) apontaram para o funcionamento de uma memória discursiva que abriu espaço para a produção de sentidos do interdiscurso sobre a família heteronormativa, o ideário religioso cristão e o imaginário social da santa e da puta, postas em condição antagônica, mas numa reciprocidade que consideramos dialética.

Analisando os elementos de dizer postos em funcionamento, identificamos uma formação discursiva machista, materializando dizeres que produzem sentidos sobre o homem "macho" e a mulher "puta", postos em relação, sem questionar o seu fundamento histórico, político, ideológico, social. Uma aposta nesta direção seria a interseccionalidade, para pensar, por exemplo, a questão étnico-racial, religiosa, de classe social, escolaridade, entre outras.

Desse lugar discursivo, o machismo materializa os efeitos da ideologia androcêntrica que orienta a organização familiar no capitalismo, sendo indispensável à exploração da força 
de trabalho das mulheres, tanto no espaço privado, quando público (guardadas as suas distinções e implicações), como também da reprodução da força de trabalho. Vê-se, portanto, que é de interesse do capital reforçar o imaginário social sobre o macho como dominante na estrutura da sociedade burguesa, enquanto fratura o estereótipo da mulher, reforçando uma dualidade entre figuras postas em condição antagônica - a santa e a puta.

A superação desse sistema de opressão/exploração das mulheres se coloca no horizonte e legitima a relação das lutas feministas com a luta de classes, num projeto revolucionário em prol da construção de uma sociedade efetivamente humana, para além do capital, da propriedade privada, do Estado, da cultura patriarcal e de todas as suas consequências.

\section{REFERÊNCIAS}

AMARAL, Maria Virgínia Borges. Discurso e relações de trabalho. Maceió: Edufal, 2005.

BUTLER, J. Problemas de gênero: feminismo e subversão da identidade. Trad. Bras. $15^{\mathrm{a}}$. ed. Rio de Janeiro: Civilização Brasileira, 2017.

CAMERON, D. Desempenhando identidade de gênero: conversa entre rapazes e construção da masculinidade heterossexual. Em: OSTERMANN, A.C.; FONTANA, B. (Orgs.). Linguagem, gênero, sexualidade: clássicos traduzidos. São Paulo: Parábola, 2010. p.120-161.

CISNE, M. Feminismo e consciência de classe social no Brasil. São Paulo: Cortez, 2014.

COURTINE, J.-J. Análise do discurso político: o discurso comunista endereçado aos cristãos. São Carlos: Claraluz, 2009.

COURTINE, J.-J. Metamorfoses do discurso político: derivas da vida pública. Trad. Bras. São Carlos: Claraluz, 2006.

FERREIRA, A.B. de Holanda. Dicionário Aurélio. 5a . ed. Belo Horizonte: Ed. Positivo, 2014.

GUIMARÃES, E. Semântica do acontecimento. Campinas: Pontes, 2002.

INDURSKY, F. Lula lá: estrutura e acontecimento. Organon, Porto Alegre, UFRGS, v. 17, n. 35, 101-121, 2003.

LEGARDINE, Claudine. Prostituição I. Em: HIRATA, H. et. al. (Orga.). Dicionário crítico do feminismo. São Paulo: Editora UNESP, 2009. p. 198-203.

ORLANDI, E.P. Análise de discurso: princípios e procedimentos. $5^{\text {a }}$. ed. Campinas: Pontes, 2003.

ORLANDI, E.P. Discurso e Texto. Campinas: Pontes, 2001.

ORLANDI, E.P. As formas do silêncio: no movimento dos sentidos. $2^{\text {a }}$. ed. São Paulo: Ed. da Unicamp, 1993.

PÊCHEUX, M. Semântica e Discurso: uma crítica à afirmação do óbvio. Trad. Bras. $4^{\text {a }}$. ed. Campinas: Pontes, 2009.

PÊCHEUX, M. O discurso: estrutura ou acontecimento. Trad. Bras. $4^{\mathrm{a}}$. ed. Campinas: Pontes, 2006.

PÊCHEUX, M. Ler o arquivo hoje. Em: ORLANDI, E.P. (Orga.). Gestos de Leitura: da história no discurso. $2^{\mathrm{a}}$. ed. Campinas: Editora da Unicamp, 1997.

PETHERSON, G. Prostituição II. Em: HIRATA, H. et. al. (Orga.). Dicionário crítico do feminismo. São Paulo: Editora UNESP, 2009. p. 203-208.

SAFFIOTI, H. A mulher na sociedade de classes: mito e realidade. $3^{\mathrm{a}}$. ed. São Paulo: Expressão Popular, 2013.

ZOPPI-FONTANA, M.G. Acontecimento, arquivo, memória: às margens da lei. Leitura, n. 30, 175-205, jul./dez. 2002. 
Artigo recebido em: nov. de 2018

Aprovado e revisado em: maio de 2019.

Publicado em: dezembro de 2019.

Para citar este texto:

ERICSON, Sóstenes; DAL'AVA, Lucas Manca. Um abanador e uma arenga: contradições e deslocamentos no trânsito dos sentidos. Entremeios [Revista de Estudos do Discurso, ISSN 2179-3514, on-line, www.entremeios.inf.br], Seção Estudos, Programa de Pós-Graduação em Ciências da Linguagem (PPGCL), Universidade do Vale do Sapucaí (UNIVÁS), Pouso Alegre (MG), vol. 19, p. 51-62, jul. - dez. 2019.

DOI: http://dx.doi.org/10.20337/ISSN2179-3514revistaENTREMEIOSvol19pagina51a62 